\title{
STUDIES ON STARLING'S LAW OF THE HEART. V. LEFT VENTRICULAR FUNCTION IN MAN
}

\author{
By EUGENE BRAUNWALD, CHARLES J. FRAHM AND JOHN ROSS, JR. with \\ THE TECHNICAL ASSISTANCE OF FREDERICK A. BULLOCK
}

(From the Cardiology Branch, National Heart Institute, Bethesda, Md.)

(Submitted for publication April 25, 1961 ; accepted June 15, 1961)

There is general agreement that the force of contraction developed by strips of cardiac muscle is a function of the length of the fibers at the onset of contraction (1-3). Similarly, in the isolated heart (4), the heart-lung preparation (5) and in the open-chest, anesthetized dog (6-8), the energy of contraction, as reflected by the external work performed by the ventricle, has been shown to be dependent upon the ventricular end-diastolic fiber length or pressure. These observations have been interpreted to be consistent with the concept enunciated by Starling in his Linacre lecture on "The Law of the Heart (9).

However, no such general agreement exists regarding the applicability of Starling's law of the heart to the circulation of human subjects. This lack of information regarding the relationship between left ventricular end-diastolic pressure (and fiber length) and the characteristics of ventricular contraction in man is understandable when it is considered that only recently have methods been developed which are suitable for the direct measurement of left ventricular pressure in subjects without cardiovascular disease (10). One of the experimental approaches which has been employed to test the validity of Starling's law has been a study of the hemodynamic response resulting from acutely induced hypervolemia (11-15). A variety of fluids has been infused in attempts to simulate in man the increase in venous return to the Starling heart-lung preparation. In several such investigations an augmentation of the total blood volume has not been associated with a significant elevation of cardiac output (13-15).

The purpose of the present investigation was to define the relationships between left ventricular end-diastolic pressure and the characteristics of left ventricular contraction in a group of subjects without cardiovascular disease. Acutely induced hypervolemia was combined with continuous ganglionic blockade in order to produce significant variations in ventricular filling and thus to permit an examination of Starling's law of the heart.

\section{METHOD}

Six male subjects averaging 25 years in age were studied. All had provided informed consent for these studies. Five of these subjects were referred to the National Heart Institute for cardiac catheterization because of the presence of systolic heart murmurs. Clinical examination was otherwise negative, chest roentgenograms and electrocardiograms were within normal limits, and these murmurs were considered to be functional in origin. The sixth subject, J.M., a 32 year old male, was studied three months after repair of a small ventricular septal defect. He had never experienced symptoms of diminished cardiac reserve, had not had cardiac enlargement on roentgenographic examination and his pulmonary arterial pressure was within normal limits (16) prior to operation as well as at the time of this study. Three or four phlebotomies were performed on each subject over a period of 7 to 10 days and the $1,500 \mathrm{ml}$ of blood so obtained was stored in solutions of sodium citrate, citric acid and dextrose. The studies were carried out 2 to 4 days after the last phlebotomy; the subjects were in a basal, postabsorptive state and had received $100 \mathrm{mg}$ of pentobarbital orally 30 minutes before their arrival in the laboratory. Local anesthesia was applied to the pharynx by means of a Pontocaine (tetracaine) spray; a small rubber balloon of the type described by Schilder, Hyatt and Fry (17) was attached to a plastic catheter and introduced into the midesophagus. The right saphenous vein was then exposed and a right heart catheterization was carried out. The pressures in the right side of the heart and pulmonary artery were within normal limits (16) in all six subjects and an inhaled radioactive krypton test (18) carried out with the catheter tip in the pulmonary artery confirmed the clinical impression that a left-toright shunt was not present. It was then decided to proceed with the remainder of the study; the catheter employed for the right heart catheterization was removed and transseptal left heart catheterization was carried out in a manner described in detail elsewhere (10). After introduction of the transseptal needle into the left atrium, a polyethylene catheter was passed through this needle into the left ventricle.

A $75 \mathrm{~cm}$ polyethylene catheter (PE no. 50) was introduced through an antecubital vein by means of percutaneous puncture, and was advanced into the superior 
vena cava or right atrium. The ganglionic blockade was then induced by an intravenous infusion of a thiophanium derivative, Arfonad (trimethaphan), a drug which also has some direct vasodilatory action $(19,20)$. The trimethaphan was administered into a peripheral vein by means of an infusion pump at a rate which was constant for each subject and which ranged from 0.6 to $3.8 \mathrm{mg}$ per minute, with an average rate of $1.7 \mathrm{mg}$ per minute; it was continued at this rate for the entire study. These infusion rates lowered systolic arterial pressure by 31 to $51 \mathrm{~mm} \mathrm{Hg}$, with an average decline of $42 \mathrm{~mm} \mathrm{Hg}$ (Table I). The effectiveness of the reduction of reactivity of the vascular system which had been achieved by the trimethaphan was tested by means of the cold pressor test; the response of systemic arterial pressure to the immersion of a foot into ice water for 1 minute was examined both before and after the infusion of trimethaphan had been begun. In all instances the elevation in arterial pressure which occurred before the trimethaphan infusion was eliminated when the cold pressor test was repeated during the trimethaphan infusion.

Cardiac output and pressures in the brachial artery, left ventricle and esophagus were then measured. Then the $1,500 \mathrm{ml}$ blood, which had been warmed to body temperature, was infused during a period of 30 to 50 minutes. Cardiac output and pressure measurements were carried out at intervals of approximately 10 to 15 minutes during the infusion. In five of the subjects a total of four measurements and in one subject three measurements of cardiac output and pressures were made.

Brachial arterial pressure was measured through an indwelling needle by means of a Statham P23A pressure transducer. A model P23D transducer was employed for the measurement of left ventricular pressure. A Statham transducer, model P.M.131T, was utilized for the measurement of intraesophageal pressure (17). Cardiac output was determined by the indicator dilution technic and was calculated in the manner described by Hamilton, Moore, Kinsman and Spurling (21). Indocyanine green dye was injected into the vena cava or right atrium via the polyethylene catheter. Arterial blood was sampled through the indwelling arterial needle and pulled through a cuvet densitometer (22) by a motor-driven syringe at a rate of $20 \mathrm{ml}$ per minute. The response of the densitometer to an instaneous change in density is 95 per cent in 1 second (23). The validity of these technics employed in the measurement of the cardiac output had first been demonstrated by a comparison with flowmeter measurements in the open-chest dog (24). In another study, utilizing identical technics, cardiac output was measured in duplicate on 20 occasions. The standard deviation of the differences between these determinations was $182 \mathrm{ml}$ per minute or 6 per cent of the mean value of the cardiac output (25).

Minute work of the left ventricle in kilogram-meters per minute was calculated as the product of mean arterial pressure in centimeters of $\mathrm{H}_{2} \mathrm{O}$, and the cardiac output in liters per minute divided by 1,000 . Left ventricular stroke work in kilogram-centimeters was calculated as the product of mean arterial pressure in centimeters of $\mathrm{H}_{2} \mathrm{O}$ and the stroke volume in milliliters divided by 100 . The tension-time index in millimeters $\mathrm{Hg} \times$ seconds was calculated from the area under the systolic portion of the arterial pressure pulse, as described previously (26). Left ventricular power in watts was calculated in five subjects by dividing left ventricular stroke work by the duration of systole. The conversion factor utilized was: 1 watt $=10,180 \mathrm{~g}-\mathrm{cm}$ per second. The duration of systole was calculated as the time interval between the onset of the isometric contraction period of the left ventricle and the time of aortic valve closure; the latter was determined by noting the instant at which the left ventricular pressure pulse reached the level of the dicrotic notch of the brachial arterial pressure pulse. The mean rate of left ventricular ejection could be determined in three subjects; it was calculated by dividing the stroke volume by the duration of ejection. In some tracings, artifacts in the pressure pulses prevented accurate estimation of these time intervals. Left ventricular end-diastolic pressure was determined as the difference between left ventricular

TABLE I

Blood pressure and heart rate before and after trimethaphan administration

\begin{tabular}{|c|c|c|c|c|c|c|}
\hline \multirow[b]{2}{*}{ Subject } & \multirow[b]{2}{*}{ Hematocrit } & \multirow{2}{*}{$\begin{array}{l}\text { Control } \\
\text { BAP }\end{array}$} & \multicolumn{2}{|c|}{ Pretransfusion } & \multicolumn{2}{|c|}{ Post-transfusion } \\
\hline & & & BAP & $\mathrm{HR}$ & BAP & HR \\
\hline $\begin{array}{l}\text { J.Ma. } \\
\text { J.M. } \\
\text { D.B. } \\
\text { B.E. } \\
\text { M.R. } \\
\text { J.B. }\end{array}$ & $\begin{array}{c}\% \\
35.2 \\
34.5 \\
28.7 \\
35.0 \\
35.0 \\
38.0\end{array}$ & $\begin{array}{c}m m H g \\
134 / 80 \\
125 / 71 \\
138 / 70 \\
144 / 64 \\
145 / 82 \\
131 / 69\end{array}$ & $\begin{array}{r}m m \mathrm{Hg} \\
101 / 69 \\
77 / 48 \\
107 / 67 \\
93 / 53 \\
104 / 60 \\
80 / 47\end{array}$ & $\begin{array}{r}91 \\
112 \\
88 \\
86 \\
107 \\
76\end{array}$ & $\begin{array}{r}m m \mathrm{Hg} \\
95 / 59 \\
115 / 81 \\
105 / 89 \\
108 / 70 \\
121 / 73 \\
122 / 71\end{array}$ & $\begin{array}{r}86 \\
106 \\
103 \\
92 \\
110 \\
100\end{array}$ \\
\hline Average & 34.8 & $136 / 73$ & $94 / 57$ & 93 & $111 / 71$ & 99 \\
\hline
\end{tabular}

* The control BAP refers to the brachial arterial pressure (systolic/diastolic) which existed at the onset of the study, after the placement of catheters but before the infusion of trimethaphan was begun. The BAP and HR (heart rate per minute) determined simultaneously with the first dilution curve, i.e., after stabilization of the circulation on trimethaphan but before the blood transfusion, are listed under "pretransfusion." Measurements under "post-transfusion" refer to observations made simultaneously with the final dilution curve, at the time of completion of blood transfusion. 
and intraesophageal pressure at the end of diastole. All values of pressure and of time intervals reported were the average of the beats occurring during two respiratory cycles. The mean arterial pressure was obtained by electrical integration.

\section{RESULTS}

All subjects were mildly anemic as a result of the repeated phlebotomies. Their hematocrits at the time of study ranged from 34.5 to 38.0 per cent, except for D.B. in whom it was 28.7 per cent. At the time that cardiac output was measured for the first time, that is, just before transfusion, the brachial arterial pressure had been depressed by trimethaphan and ranged between $77 / 48$ and $107 / 67$, with an average level of $94 / 67$ $\mathrm{mm} \mathrm{Hg}$. In spite of the hypotension, these subjects did not present the clinical appearance gen-

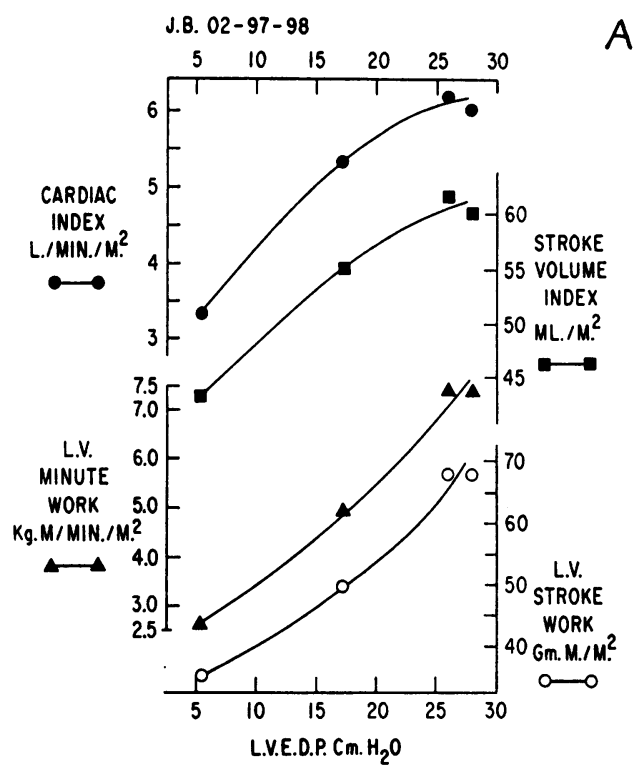

A
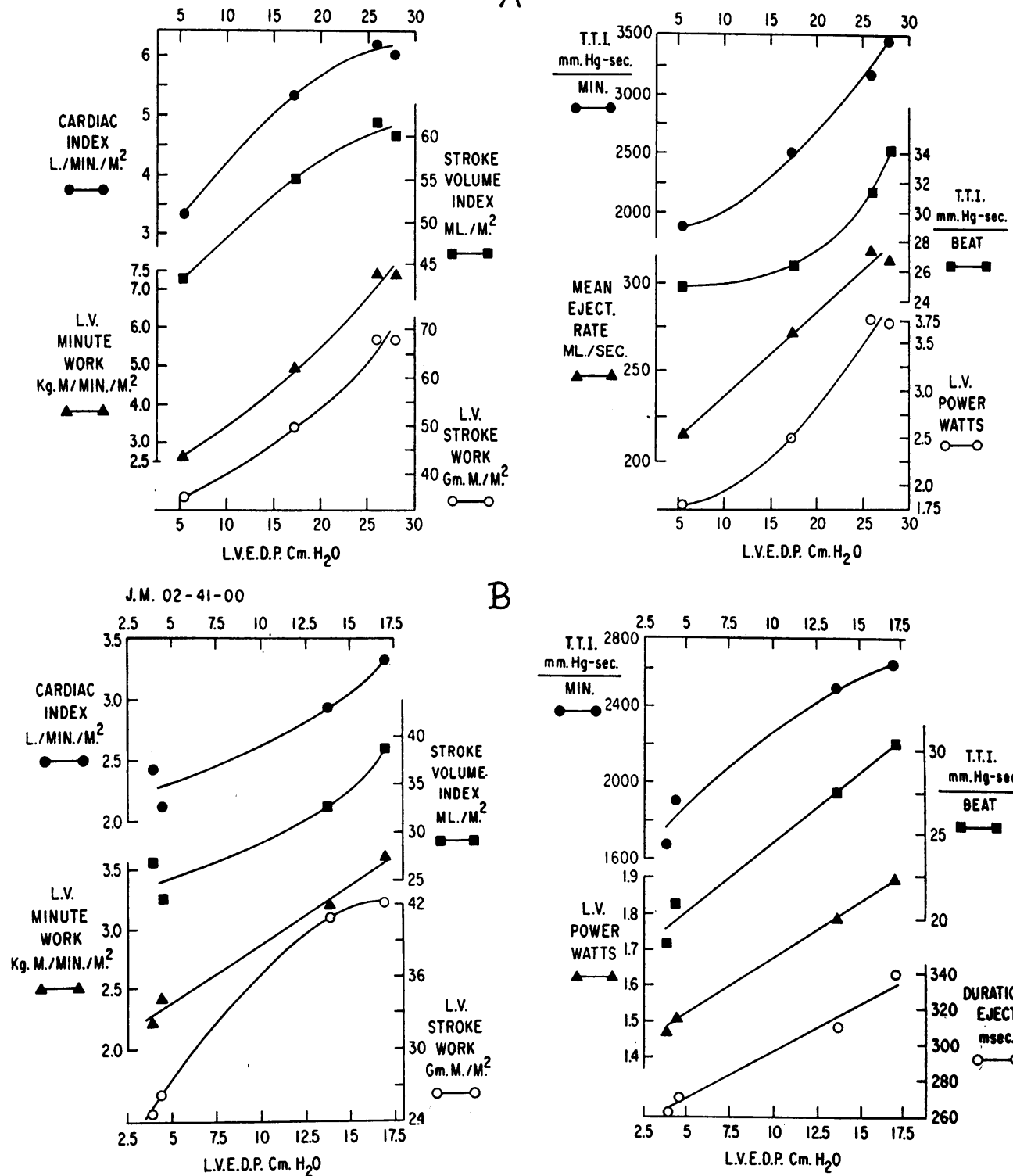

B

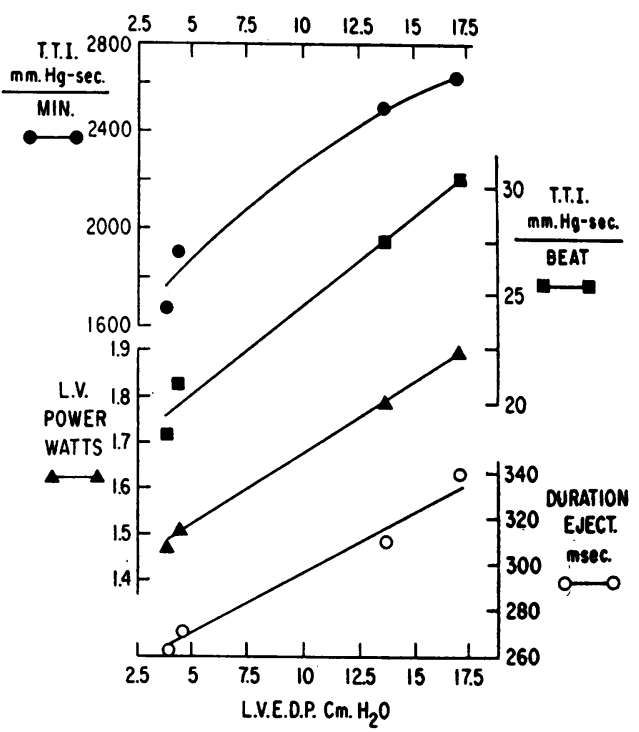

Fig. 1. Relationships betWeEn L.V.E.D.P. (DIFFerence betWeEN LEFt ventricular and INTRAESOPHAGEAL PRESSURE AT THE END OF DIASTOLE) AND VARIOUS PARAMETERS OF LEFT VENTRICULAR (L.V.) PERFORMANCE IN SIX SUBJECTS. T.T.I. refers to the tension-time index; EJECT. refers to ejection. 


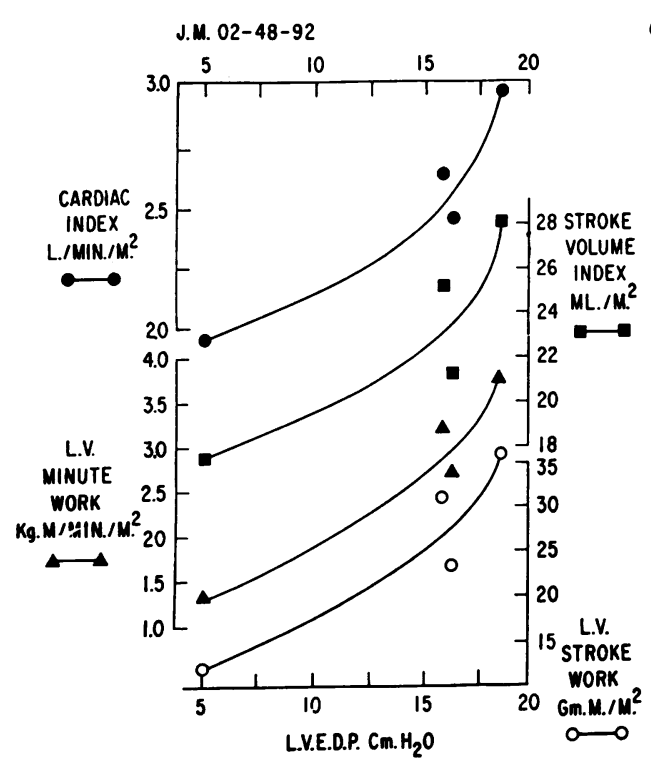

D.8. $02-67-95$

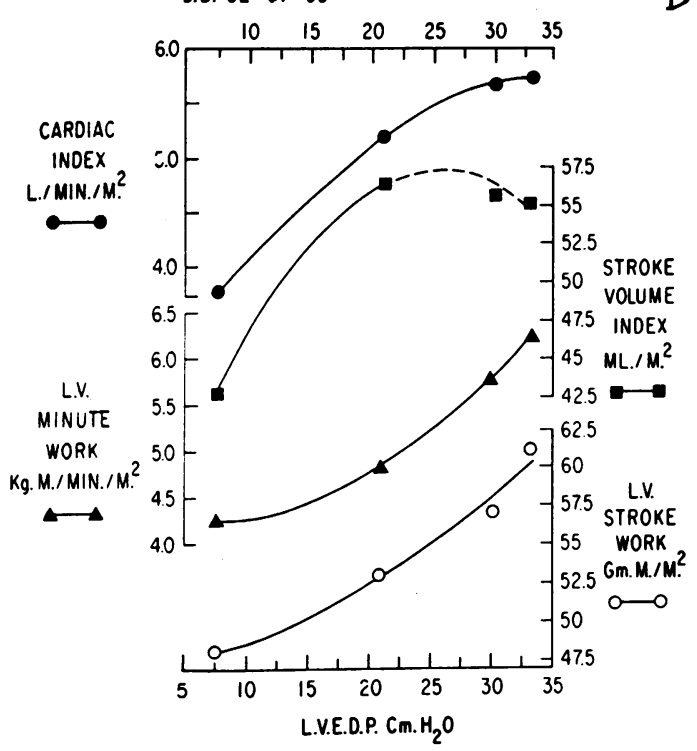

C

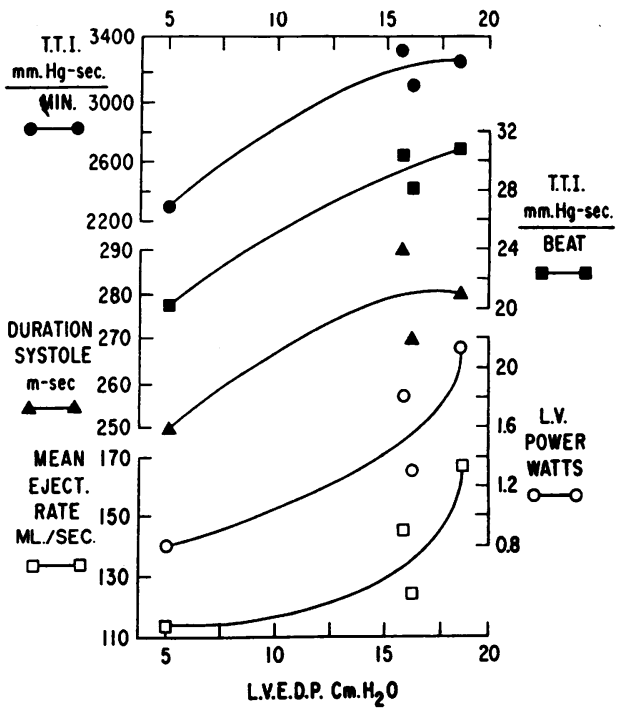

D

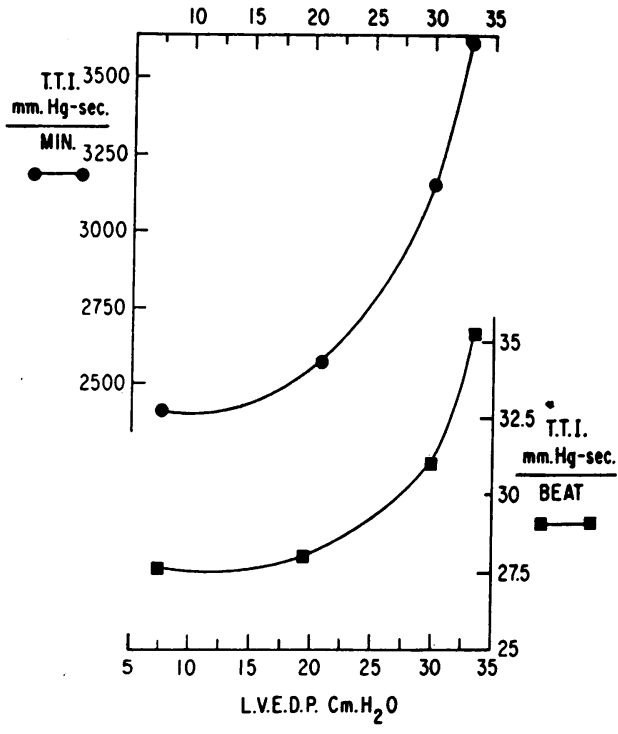

Fig. 1.-Continued

erally associated with shock; before transfusion the cardiac index exceeded $2.0 \mathrm{~L}$ per minute per $\mathrm{m}^{2}$ in all subjects and averaged $3.15 \mathrm{~L}$ per minute per $\mathrm{m}^{2}$.

As a result of the transfusion the arterial pressure rose significantly in four of the subjects, declined in one (J.Ma) and showed little change in one (D.B.). Heart rate changed only slightly in four subjects and increased significantly in two (D.B. and J.B.) (Table I). The results obtained in each subject are shown in Figure 1.
The left ventricular end-diastolic pressure at the onset of the blood infusion ranged from 1.2 to $7.6 \mathrm{~cm} \mathrm{H}_{2} \mathrm{O}$ and the average level was $4.8 \mathrm{~cm} \mathrm{H}_{2} \mathrm{O}$. A significant elevation of left ventricular end-diastolic pressure occurred; at the completion of the infusion these pressures ranged from 17.0 to 33.1 with an average level of $22.2 \mathrm{~cm} \mathrm{H}_{2} \mathrm{O}$. There were only slight alterations of intraesophageal pressure during the course of the blood infusions. The maximal change of this pressure in any subject was $3.0 \mathrm{~cm} \mathrm{H}_{2} \mathrm{O}$ and the reported 
changes of "effective" end-diastolic pressure resulted primarily from alterations of the recorded intraventricular pressure. Representative pressure tracings are reproduced in Figure 2 . In every instance the cardiac output rose along with the left ventricular end-diastolic pressure. The left ventricular work per minute and the left ventricular stroke work, the tension-time index per minute and per beat, the left ventricular power, duration of ejection and mean rate of left ventricular ejection also rose as the transfusion continued and as the effective left ventricular filling pressure rose (Figure 1). In five subjects stroke volume became elevated as left ventricular diastolic pressure rose. In the sixth subject (Figure $1 \mathrm{~F}$ ) the stroke volume rose substantially at the beginning of the infusion, but declined slightly as it was continued.

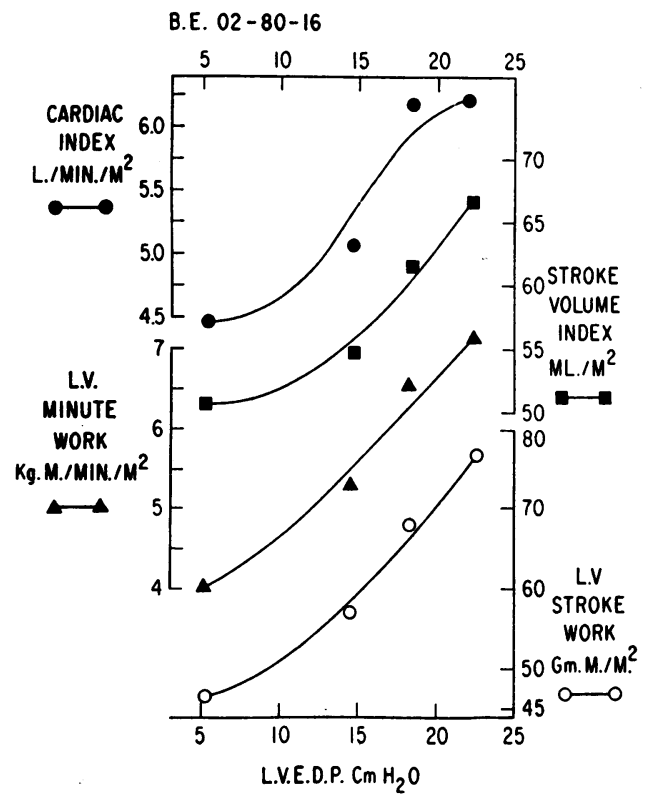

E
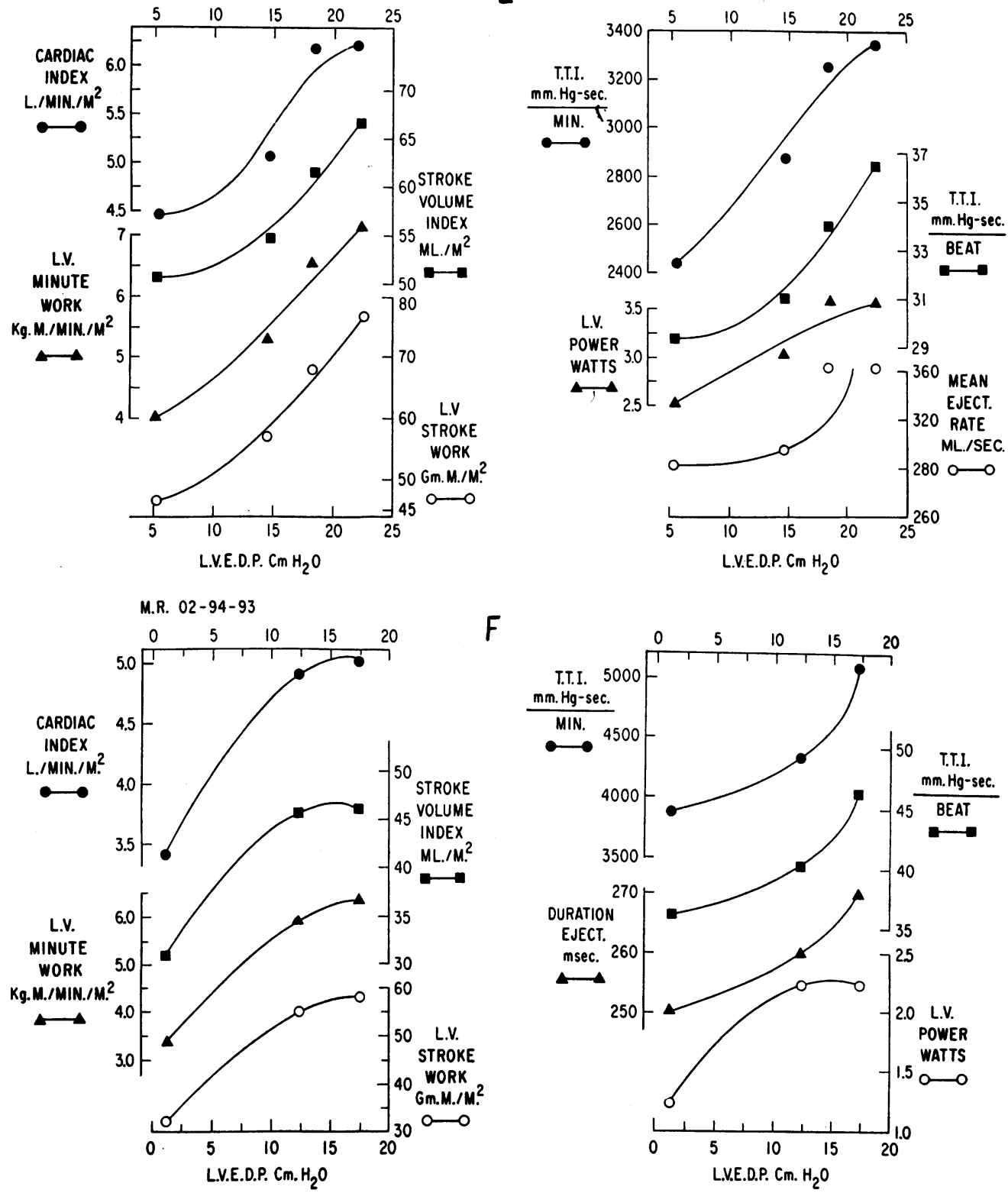

$F$

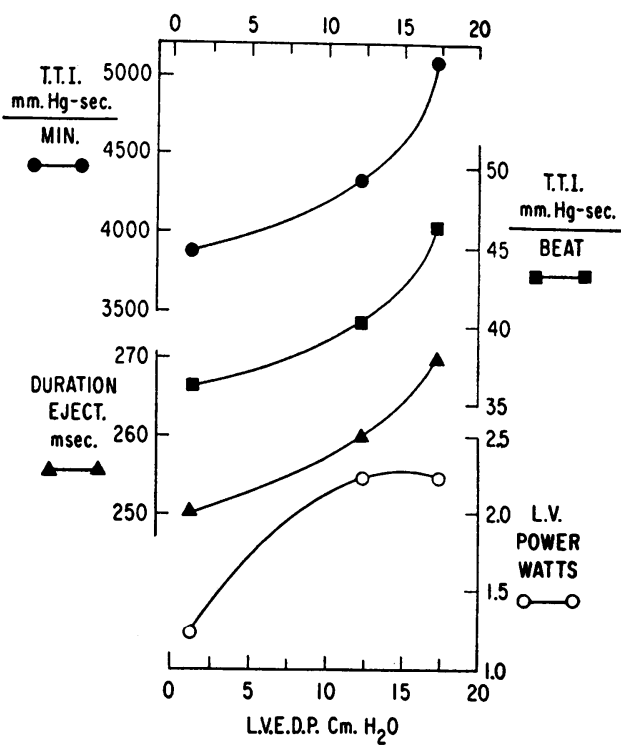

Fig. 1.-Continued 


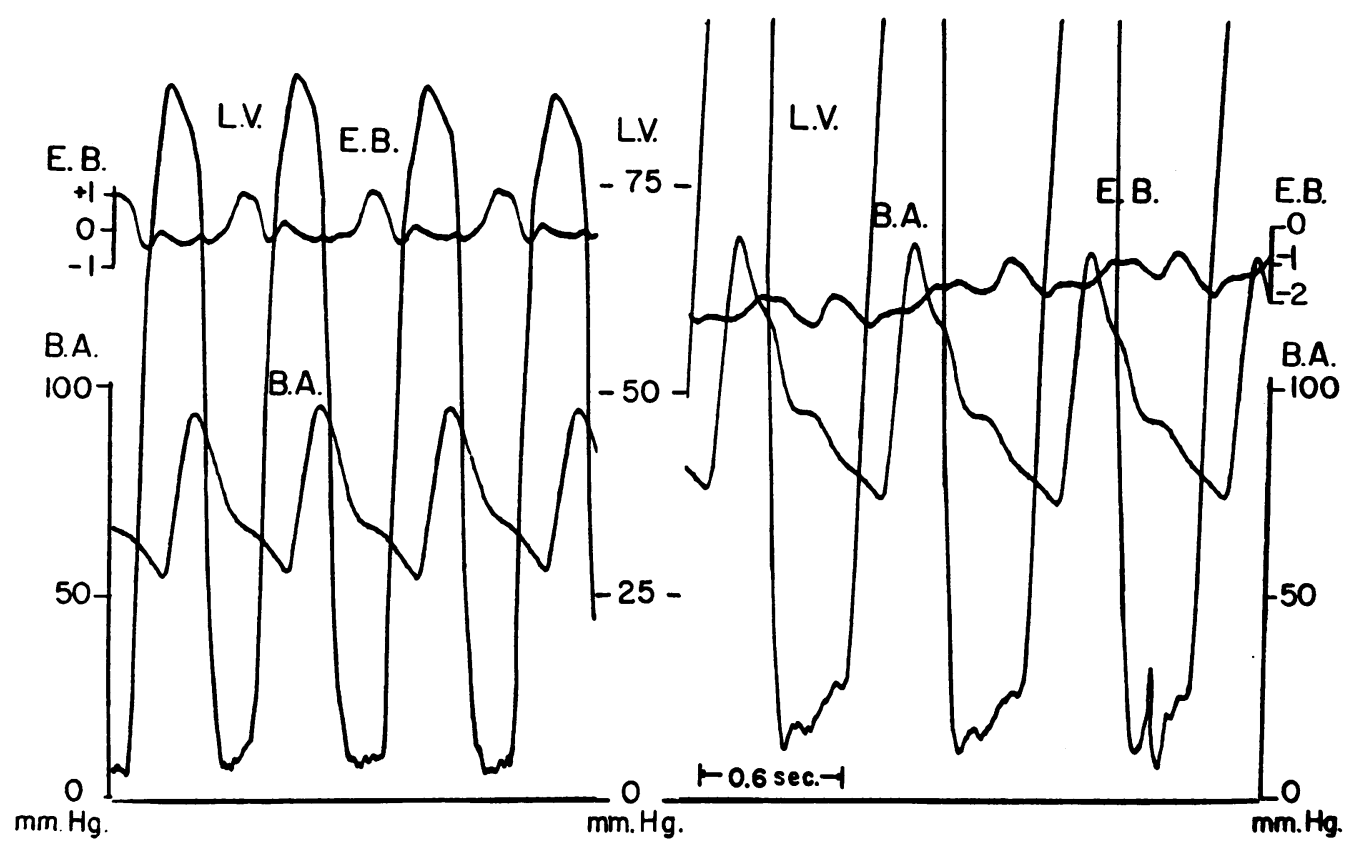

Fig. 2. Simultaneous pressures ReCorded from the left ventricle (L.V.), brachial artery (B.A.) AND ESOPHAGUS (E.B.) BEFORE TRANSFUSION (LEFT) AND DURING TRANSFUSION (RIGHT).

\section{DISCUSSION}

It is clear from the studies of Sarnoff and his collaborators, carried out on open-chest, anesthetized dogs, that humoral (8) and neurogenic (27, 28) influences are capable of profoundly altering myocardial contractility, i.e., of elevating or depressing the ventricular function curve. Chapman, Baker and Mitchell have shown that the Frank-Starling principle applies to the closedchest, anesthetized dog at rest and that during mild exercise the left ventricle operates at different "functional levels," i.e., with elevated ventricular function curves (29). Observations in this laboratory have demonstrated that norepinephrine is capable of markedly elevating the ventricular function curve in the closed-chest, unanesthetized $\operatorname{dog}(30)$. As has recently been indicated by Chapman (31), it would appear likely that humoral and neurogenic factors also exert similar influences in the intact human subject and that these factors may sometimes obscure the underlying relationship between ventricular end-diastolic pressure and the force of ventricular contraction. The purpose of the present investigation was not to assess the relative importance of these neurohumoral influences and of the Frank-Starling mechanism in the control of cardiac function in the intact organism; rather, it was designed to determine whether the Frank-Starling mechanism applies to the human heart when alterations of the neurohumoral factors are reduced to a minimum.

In order to accomplish this purpose, it would appear essential to relate ventricular end-diastolic fiber length or end-diastolic volume to the characteristics of ventricular contraction. Recent observations in the dog have demonstrated that the relationship between effective left ventricular enddiastolic pressure and segment length is unaffected by stimulation of the cardiac sympathetic nerves or of the vagi (32) and by large changes of systemic arterial pressure and of cardiac output (33). It has also been shown in man that in the absence of tachycardia, changes in the effective left ventricular end-diastolic pressure may be utilized to indicate alterations in left ventricular dimensions (34). Thus, without the availability of a suitable technic capable of providing accurate serial measurements of left ventricular volume in man, left ventricular and intraesophageal pressures were measured in order to permit measurement of changes in effective left ventricular enddiastolic pressure.

It is well recognized that when the intraesopha- 
geal pressure is determined with the subject in the supine position, it does not provide an accurate measurement of the absolute level of intrapleural pressure $(35,36)$. However, as is evident in Figure 3 of the paper by Mead and Gaensler (35), even in this position, changes in the intraesophageal pressure satisfactorily reflect alterations in the intrapleural pressure. Accordingly, the difference between the left ventricular end-diastolic pressure and the intraesophageal pressure was measured during this study. Although no claim is made that the absolute effective end-diastolic pressure was provided by these measurements, it is felt that the magnitude of changes in effective left ventricular end-diastolic pressure which occurred as a result of the infusion could be determined with accuracy in this manner.

The importance of reflexes mediated through the autonomic nervous system in the control of myocardial contractility (27), as well as of the tone of the venous $(37,38)$ and arteriolar (39) beds is now well established. Rapid expansion of the blood volume could be expected to stimulate baroreceptors in the carotid sinuses, the aortic arch, the heart and lungs, as well as in the venous beds. As a consequence, it would be anticipated that a decline in ventricular and atrial contractility (27), bradycardia, venodilatation (37) and arteriolar dilatation (39) would occur. In this manner, reflex depression of the circulation could be expected to limit any augmentation of cardiac performance which might result from an increase in left ventricular end-diastolic fiber length, if the Frank-Starling mechanism were operative. In support of this hypothesis, it has been shown that the infusion of $1,500 \mathrm{ml}$ of blood into intact subjects did not result in an augmentation of the central blood volume, of cardiac output and of cardiac work. It was postulated that the transfusion led to reflex venodilatation which, in turn, resulted in a tendency for the infused blood to pool in the venous system and thereby to diminish the volume of blood in the heart and lungs. However, when in the same subjects the activity of the autonomic nervous system was reduced by means of a ganglionic blocking agent, the transfusion of $1,500 \mathrm{ml}$ of blood resulted in a striking augmentation of central blood volume and of cardiac output and work (15). Accordingly, with these observations in mind, it was considered that in order to ascertain whether the left ventricular enddiastolic pressure is a fundamental determinant of left ventricular performance, the blood should be infused after inhibition of the autonomic nervous system. The present investigation was therefore performed with the subjects receiving a continuous infusion of trimethaphan. The dose of this drug was sufficient to lower the arterial pressure significantly and to abolish the elevation of arterial pressure which normally occurs during the cold pressor test (40). It was thought that these hemodynamic alterations were produced by the ganglionic blocking activities of the drug (19, 40). Since there was no evidence of coronary artery disease in any of the subjects studied, it is considered unlikely that the moderate hypotension induced by the trimethaphan interfered sufficiently with coronary perfusion to depress cardiac function. This view is also supported by the observation that electrocardiographic alterations associated with myocardial ischemia did not occur.

In all six subjects studied the blood transfusion resulted in a striking elevation of left ventricular end-diastolic pressure. The magnitude of this increase in pressure is presumably related to the large increase in ventricular diastolic volume which is believed to have accompanied the transfusion. This was accompanied by an augmentation of left ventricular performance; the latter was evidenced by the increases which occurred in the cardiac output per minute and per stroke, the left ventricular work per minute and per stroke, the power (work per systolic second) of the left ventricle and the mean rate of left ventricular ejection (Figure 1). In addition, the tension-time index per minute and per beat also rose along with left ventricular end-diastolic pressure. The tensiontime index has been shown in previous studies (26) to be the hemodynamic parameter which correlates most closely with myocardial oxygen consumption. These results then are in accord with the concept that Starling's law of the heart applies to the human subject.

An abbreviation of left ventricular systole generally accompanies the augmentation of cardiac performance which results from sympathetic stimulation (28); in these experiments, however, the duration of left ventricular systole increased (Figure $1 ; \mathrm{B}, \mathrm{C}$ and $\mathrm{F}$ ). These results are not unexpected, since the observations were carried out 
during ganglionic blockade and are compatible with the view that the hemodynamic changes observed reflected properties inherent in the cardiac muscle.

It was demonstrated in earlier studies carried out in this laboratory that marked alterations in left ventricular end-diastolic segment length and pressure occur as a consequence of variations in the duration of filling in the presence of atrial fibrillation (34) or as a result of variations in the effectiveness of atrial contraction in atrioventricular dissociation (41); the force of left ventricular contraction was found, in each instance, to be a function of the left ventricular end-diastolic segment length and, in the absence of tachycardia, of the left ventricular end-diastolic pressure as well. These results are entirely in accord with those obtained in the present investigation in which a different technic for varying ventricular filling was utilized. Evidence has also been presented recently that the force of atrial contraction in man is a function of the atrial pressure existing at the onset of atrial contraction (41), suggesting that the atria as well as the ventricles behave in accordance with Starling's law of the heart.

\section{SUMMARY}

This investigation was designed to determine whether Starling's law of the heart is applicable to man. Changes in effective left ventricular enddiastolic pressure were determined by measuring left ventricular pressure with a catheter introduced through the atrial septum, and intraesophageal pressure with a balloon. The activity of the autonomic nervous system was reduced with an infusion of Arfonad (trimethaphan), which was continued at a constant rate throughout the study. The reduction in circulatory reactivity produced by this drug was indicated by the absence of an arterial pressure elevation during the cold pressor test. Measurements of cardiac output, stroke volume, left ventricular work, power, tension-time index, and of the duration and mean rate of left ventricular ejection were carried out before, during the course of, and upon completion of a transfusion of $1,500 \mathrm{ml}$ of the subject's own blood. This transfusion resulted in a significant elevation of left ventricular end-diastolic pressure in each subject, the average level rising from 4.8 to $22.2 \mathrm{~cm} \mathrm{H}_{2} \mathrm{O}$. In each subject, as the left ventricular end-diastolic pressure rose, left ventricu- lar performance, as reflected in the parameters listed above, also became augmented. These data are consistent with the hypothesis that under the conditions of these experiments the end-diastolic pressure is an important determinant of the characteristics of ventricular contraction and that Starling's law of the heart is applicable to man.

\section{ACKNOWLEDGMENT}

The cooperation of Dr. Robert L. Frye at the beginning of this study is gratefully acknowledged.

\section{REFERENCES}

1. Lundin, G. Mechanical properties of cardiac muscle. Acta physiol. scand. 1944, 7, suppl. 20.

2. Abbott, B. C., and Mommaerts, W. F. H. M. A study of inotropic mechanisms in the papillary muscle preparation. J. gen. Physiol. 1959, 42, 533.

3. Sonnenblick, E. H., and McCallum, Z. T. Active state, force velocity relationships and inotropic mechanisms in mammalian papillary muscle. Fed. Proc. 1961, 20, 126.

4. Frank, O. Zur Dynamik des Herzmuskels. Z. Biol. $1895,32,370$.

5. Patterson, S. W., Piper, H., and Starling, E. H. Regulation of the heart beat. J. Physiol. (Lond.) 1914, 48, 465.

6. Wiggers, C. J., and Katz, L. N. The contour of the ventricular volume curves under different conditions. Amer. J. Physiol. 1922, 58, 1922.

7. Ferguson, T. B., Shadle, O. W., and Gregg, D. E. Effect of blood and saline infusion on ventricular end diastolic pressure, stroke work, stroke volume and cardiac output in the open and closed chest dog. Circ. Res. 1953, 1, 62.

8. Sarnoff, S. J., and Berglund, E. Ventricular function. I. Starling's law of the heart studied by means of simultaneous right and left ventricular function curves in the dog. Circulation 1954, 9, 706.

9. Starling, E. H. The Linacre Lecture on the Law of the Heart (Cambridge, 1915). London, Longmans, Green, 1918.

10. Ross, J., Jr., Braunwald, E., and Morrow, A. G. Left heart catheterization by the transseptal route. A description of the technic and its applications. Circulation 1960, 22, 927.

11. McMichael, J., and Sharpey-Schafer, E. P. Cardiac output in man by a direct Fick method. Effects of posture, venous pressure change, atropine, and adrenaline. Brit. Heart J. 1944, 6, 33.

12. Witham, A. C., Fleming, J. W., and Bloom, W. L. The effect of intravenous administration of dextran on cardiac output and other circulatory dynamics. J. clin. Invest. 1951, 30, 897.

13. Fleming, J. W., and Bloom, W. L. Further observations on the hemodynamic effect of plasma vol- 
ume expansion by dextran. J. clin. Invest. 1957, $36,1233$.

14. Schnabel, T. G., Jr., Eliasch, H., Thomasson, B., and Werkö, L. The effect of experimentally induced hypervolemia on cardiac function in normal subjects and patients with mitral stenosis. J. clin. Invest. 1959, 38, 117.

15. Frye, R. L., and Braunwald, E. Studies on Starling's law of the heart. I. The circulatory response to acute hypervolemia and its modification by ganglionic blockade. J. clin. Invest. 1960, 39, 1043.

16. Fowler, N. O., Westcott, R. N., and Scott, R. C. Normal pressure in the right heart and pulmonary artery. Amer. Heart J. 1953, 46, 264.

17. Schilder, D. P., Hyatt, R. E., and Fry, D. L. An improved balloon system for measuring intraesophageal pressure. J. appl. Physiol. 1959, 14, 1057.

18. Sanders, R. J., and Morrow, A. G. The identification and quantification of left-to-right circulatory shunts: A new diagnostic method utilizing the inhalation of a radioactive gas, $\mathrm{Kr}^{85}$. Amer. J. Med. 1959, 26, 508 .

19. Randali, L. O., Peterson, W. G., and Lehmann, G. The ganglionic blocking action of thiophanium derivatives. J. Pharmacol. exp. Ther. 1949, 97, 48.

20. McCubbin, J. W., and Page, I. H. Nature of the hypotensive action of thiophanium derivative ( $\mathrm{RO}$ 2-2222) in dogs. J. Pharmacol. exp. Ther. 1952, $105,437$.

21. Hamilton, W. F., Moore, J. W., Kinsman, J. M., and Spurling, R. G. Studies on the circulation. IV. Further analysis of the injection method, and of changes in hemodynamics under physiological and pathological conditions. Amer. J. Physiol. 1932, 99, 534.

22. Gilford, S. R., Gregg, D. E., Shadle, O. W., Ferguson, T. B., and Marzetta, L. A. An improved cuvette densitometer for cardiac output determination by the dye-dilution method. Rev. sci. Instrum. 1953, 24, 696.

23. Sabiston, D. C., Jr., Khouri, E. M., and Gregg, D. E. Use and application of the cuvette densitometer as an oximeter. Circulat. Res. 1957, 5, 125.

24. Braunwald, E., Binion, J. T., Morgan, W. L., Jr., and Sarnoff, S. J. Alterations in central blood volume and cardiac output induced by positive pressure breathing and counteracted by metaraminol (Aramine). Circulat. Res. 1957, 5, 670.

25. Chidsey, C. A., Frye, R. L., Kahler, R. L., and Braunwald, E. The influence of syrosingopine on the cardiovascular response to acute hypoxemia and exercise. Circulat. Res. In press.

26. Sarnoff, S. J., Braunwald, E., Welch, G. H., Jr., Case, R. B., Stainsby, W. N., and Macruz, R. Hemodynamic determinants of the oxygen consumption of the heart with special reference to the tension-time index. Amer. J. Physiol. 1958, $192,148$.
27. Sarnoff, S. J., Gilmore, J. P., Brockman, S. K., Mitchell, J. H., and Linden, R. J. Regulation of ventricular contraction by the carotid sinus; its effect on atrial and ventricular dynamics. Circulat. Res. 1960, 8, 1123.

28. Sarnoff, S. J., Brockman, S. K., Gilmore, J. P., Linden, R. J., and Mitchell, J. H. Regulation of ventricular contraction: Influence of cardiac sympathetic and vagal nerve stimulation on atrial and ventricular dynamics. Circulat. Res. 1960, 8, 1108.

29. Chapman, C. B., Baker, O., and Mitchell, J. H. Left ventricular function at rest and during exercise. J. clin. Invest. 1959, 38, 1202.

30. Warbasse, J. R., Aygen, M. M., and Braunwald, E. Studies on Starling's law of the heart. VI. Ventricular function in the closed-chest dog. In preparation.

31. Chapman, C. B. On the nature of cardiac control. Ann. intern. Med. 1960, 53, 1272.

32. Mitchell, J. H., Linden, R. J., and Sarnoff, S. J. Influence of cardiac sympathetic and vagal nerve stimulation on the relation between left ventricular diastolic pressure and myocardial segment length. Circulat. Res. 1960, 8, 1100.

33. Braunwald, E., Frye, R. L., and Ross, J., Jr. Studies on Starling's law of the heart. II. Determinants of the relationship between left ventricular end-diastolic pressure and circumference. Circulat. Res. 1960, 8, 1254.

34. Braunwald, E., Frye, R. L., Aygen, M. M., and Gilbert, J. W., Jr. Studies on Starling's law of the heart. III. Observations in patients with mitral stenosis and atrial fibrillation on the relationships between left ventricular end-diastolic segment length, filling pressure, and the characteristics of ventricular contraction. J. clin. Invest. 1960 , 39, 1874.

35. Mead, J., and Gaensler, E. A. Esophageal and pleural pressures in man, upright and supine. $J$. appl. Physiol. 1959, 14, 81.

36. Knowles, J. H., Hong, S. K., and Rahn, H. Possible errors using esophageal balloon in determination of pressure-volume characteristics of the lung and thoracic cage. J. appl. Physiol. 1959, 14, 525.

37. Alexander, R. S. Participation of venomotor system in pressor reflexes. Circulat. Res. 1954, 2, 405.

38. Ross, J., Jr., Frahm, C. J., and Braunwald, E. Influence of the carotid baroreceptors and of vasoactive drugs on systemic vascular volume and venous distensibility. Circulat. Res. 1961, 9, 75.

39. Folkow, B. Nervous control of blood vessels. Physiol. Rev. 1955, 35, 629.

40. Finnerty, F. A., Jr., and Freis, E. D. Experimental and clinical evaluation in man of Hexamethonium $\left(\mathrm{C}_{6}\right)$, a new ganglionic blocking agent. Circulation 1950, 2, 828.

41. Braunwald, E., and Frahm, C. J. Studies on Starling's law of the heart. IV. Observations on the hemodynamic functions of the left atrium in man. Circulation. In press. 